\title{
EFFECT OF LOAD FLANK ANGLE MODIFICATIONS ON THE STRUCTURAL INTEGRITY OF BUTTRESS THREADED CONNECTIONS
}

\author{
T. Galle ${ }^{1}$, J. Van Wittenberghe ${ }^{1}$, F. Camelia Jula ${ }^{2}$, W. De Waele ${ }^{1}$ and P. De Baets ${ }^{1}$ \\ ${ }^{1}$ Ghent University, Laboratory Soete, Belgium \\ ${ }^{2}$ Technical university of Cluj-Napoca, Romania
}

\begin{abstract}
One of the main requirements of threaded \& coupled connections used in oil-producing wells is the ability to resist high tensile loads. In order to ensure integrity under ever-increasing loads, the geometric parameters of the connection can be modified. In this paper, an FEA study of a 4.5 inch casing connection is reported to examine the effects of a modified load angle in combination with high tensile forces. The focus is on two failure mechanisms: jump-out and plastically deformed zones. Furthermore, a relative motion of pin and box at the contact regions is observed. It is concluded that using a negative load flank might be beneficial in order to prevent jump-out. At the same time, the deformations at the roots of the last engaged threads of the pin appear to be larger and relative sliding increases. Despite an optimization against one failure mechanism, the connection might fail as a result of an inevitable reduction of resistance against another.
\end{abstract}

Keywords: threaded connection; casing; modified load angle; failure mechanisms

\section{INTRODUCTION}

Threaded pipe connections are widely used in the oil and gas industry for well completion, drill strings and risers in offshore applications[1]. When comparing the nature of threaded connections with welded connections, major advantages can be identified. On one hand, the limited time which is required to connect two pipes in the field reduces the time to complete wells drastically. On the other hand, it is possible to break up the threaded joints without causing excessive plastic deformations. The ability to reuse the pipes in other wells is of vital importance for drill pipes.

Due to the introduction of high performance connections which are characterized by a unique geometry consisting of a metal-to-metal seal, torque shoulder and thread profile[2], companies are able to build deeper wells in more extreme conditions. When taking into account the increased depths and hostile environmental effects, different failure mechanisms have to be examined in order to optimise the threaded joint.

In this study, two frequently occurring types of failure are being examined. Drilling deeper wells results in the use of longer casing and drill strings, which implies an increase of weight leading to higher axial loads. These axial forces can cause the threaded joints to separate due to a phenomenon known as jump-out[3]. In order to reuse the connections when applied in drill strings, one of the prerequisites dictates that plastic deformation is non-existent or very limited. For this reason, the axial plastic strains within the threads can be used as the basis of a criterion to quantify the plasticity occurring in the connection.

A numerical study on a 4.5 inch threaded-and-coupled connection (T\&C) with standard API buttress threads and one with buttress threads with modified load angle subjected to an axial tensile load is carried out and a comparison is made. As a result, an indication of which failure mechanism is more likely to occur becomes visible. 


\section{LITERATURE ON LOAD FLANK MODIFICATIONS}

Despite the required increase of outer diameter of the overall string, T\&C connections are often preferred when a high mechanical efficiency is required, as shown in Figure 1. The mechanical efficiency is defined as follows:

$$
\text { Mechanical efficiency }=\frac{\text { Mechanical strength of the connection }}{\text { Pipe-body strength }}
$$

In order to increase the mechanical efficiency, the geometrical parameters of the connection can be altered. Little information is published about such modifications to standard buttress connections. Changing the load angle of modified buttress threads used in premium connections and their effects are mentioned in a limited number of papers.

Hilbert et al [4] indicate that hooked threads, having a negative load flank angle, are beneficial in order to reduce the relative sliding and the radial separation between pin and box, which often leads to jump-out failure when tensile loads are applied. This indicates an increased tensile and bending capacity of the connection. Despite the fact premium connections do not rely on the thread to assure its sealing capabilities, Takano et al [5] state that the use of a negative load flank angle is improving the external pressure capacity. Furthermore, the load flank angle is directly responsible for the location of stress concentrations on the contacting load flanks, occurring during make up. These concentrations can be redirected to lower portions of the pin thread, which have the highest strength, by modifying the load angle. In a similar way, the galling resistance of the joint can be enhanced.

\section{NUMERICAL ANALYSIS}

\subsection{Creation of the models}

An in-house developed, parametric program is used to model a series of modified 4.5 inch buttress connections with load flanks ranging from a positive 13 degrees, up to a negative 13 degrees with an increment of 2 degrees. The length of the pitch was kept constant in all models, as seen in Figure 2. A pipe steel with a yield strength of $736 \mathrm{MPa}$ and an ultimate tensile strength of $869 \mathrm{MPa}$ is applied in combination with axial loads varying between $0 \mathrm{MPa}$ and up to $650 \mathrm{MPa}$. The results reported in this paper do not take preload resulting from initial make up into consideration.

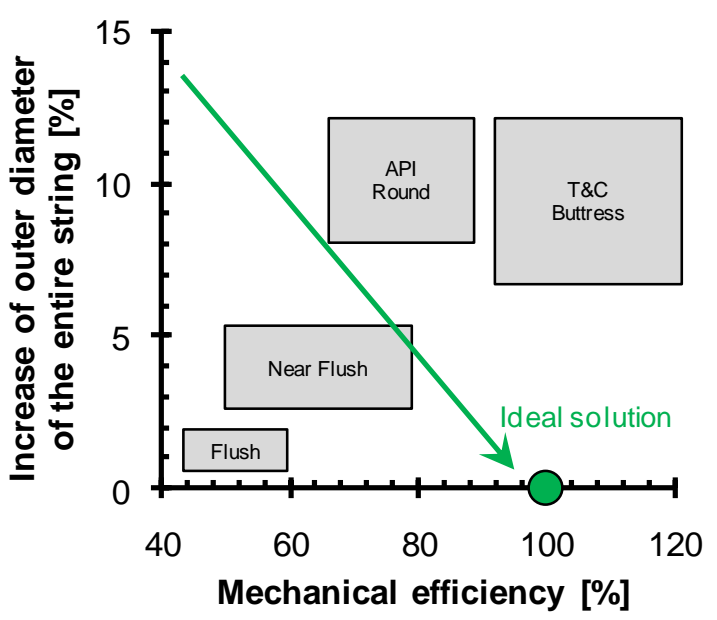

Figure 1: Overview of connections based on mechanical efficiency and their increase of overall outer diameter (OD) of the string, relative to the used pipes.

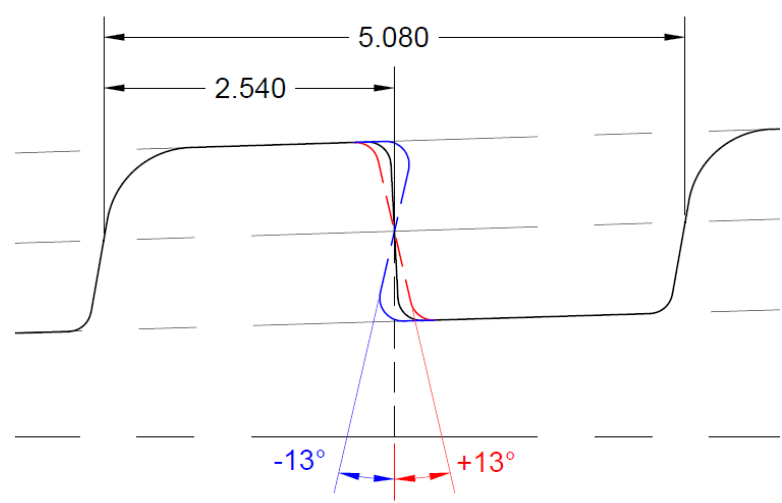

Figure 2: Representation of a standard buttress thread (black) with indication of the modified load flank angle ranging from -13 (blue) up to +13 degrees (red).

Because of a very fine mesh size of approximately $15 \mu \mathrm{m}$ at the contact surface of the threads, accurate information can be gathered to evaluate the tendency of the two considered failure mechanisms. An example of a threaded connection with a regular API buttress thread, containing a positive load flank angle of 3 degrees, is given at the bottom of Figure 3 . 


\subsection{Results}

Van Wittenberghe et al. [6] pointed out that the most critical part of API Line Pipe connections is located at the last engaged thread (LET). Assanelli et al. [7] showed that similar conclusions can be drawn for API buttress couplings. These conclusions were confirmed and special attention was given to the three last engaged threads, indicated as threads 17,18 and 19 in Figure 3 . These threads clearly show the tendency to create shear bands in the pin upon axial tensile load. The shear bands start at the load flanks in contact and migrate towards the surface at the cut-off crest. In these regions, plastic deformation occurs and the reusability of the joint is questionable when the magnitude of these strains becomes excessively high. On the other hand, the contact between the crest of the box and the root of the pin is not maintained and increases with higher tensile loads. Once the separation becomes larger than the height of the thread involved, failure by jump-out is likely to occur [8].

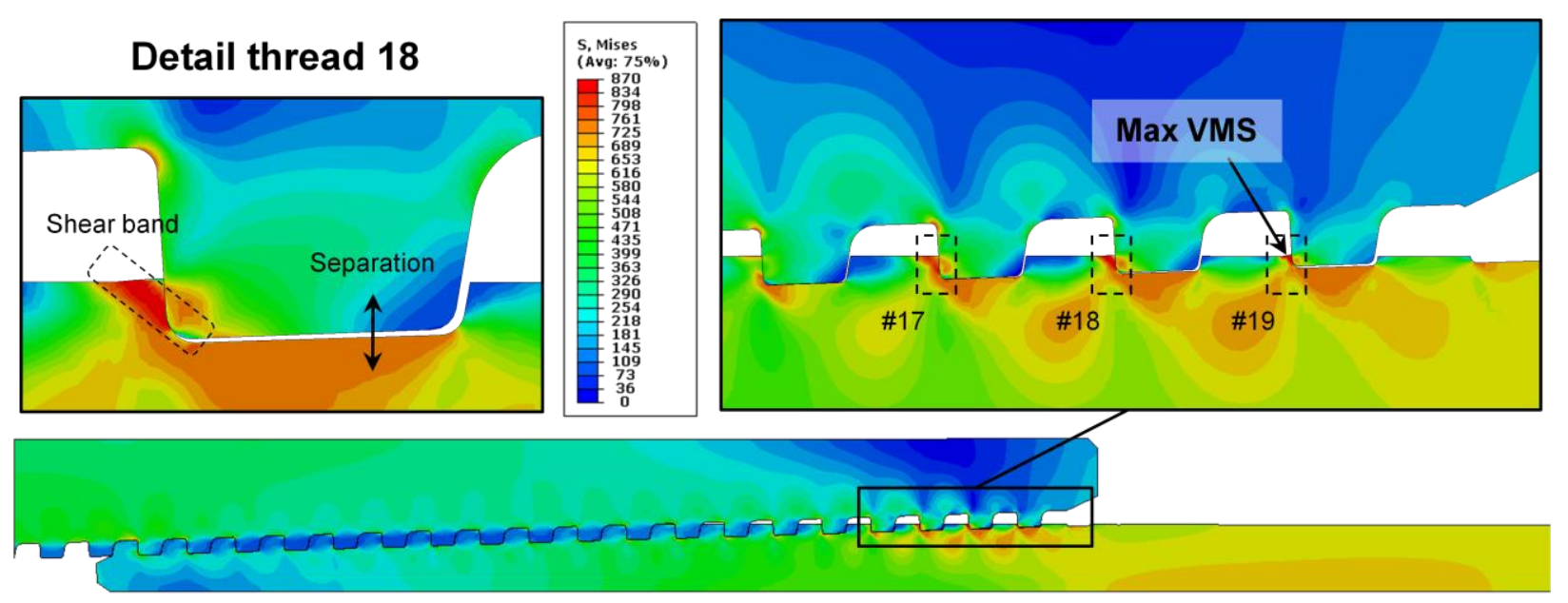

Figure 3: Example of a standard buttress connection with an applied tensile load of $650 \mathrm{MPa}$. The last engaged thread represents the most critical part of the connection due to the high Von Mises stresses (Max VMS). In the detail of thread 18, a shear band representing a plasticised region and the separation at the thread root of the pin is visible.

\subsubsection{Plasticity}

From Figure 3 it is visible that zones of high stresses, exceeding the yield stress, occur at the load flanks of the last engaged threads, resulting in plastic deformations. In order to ensure reusability, these deformations have to be kept to a minimum.

In an effort to quantify the plasticity, the axial plastic strain at the pin crests caused by the tensile loadings is extracted. Figure 4 shows that the plastic zones are concentrated at the roots of the pin near the load flanks of the vanishing threads of the coupling. When the tensile load is increased, the plastic zones grow towards the crest under an angle of approximately 45 degrees. The results for a tensile load of $350 \mathrm{MPa}$ and $650 \mathrm{MPa}$ for both a load flank angle of +13 and -13 degrees (respectively P13 and M13) are presented in Figure 5 and Figure 6 for the cut-off crests of threads 18 and 19. Plasticity occurs near the load flank of the thread and is most severe in the LET due to the decreased height of the incomplete thread. The insufficient quantity of material able to resist the acting contact pressures on the load flanks results in an axial shifting of these areas.

When increasing the axial load, the magnitude of plasticity increases and the maximum strain location shifts towards the centre of the crest. This can be explained by considering a relative motion between pin and box. Figure 4 shows that the box threads deform the pin crests at the right hand side. Despite the similarities related to location and mechanism of the plastic zones, a negative load angle appears to be disadvantageous when plasticity has to be avoided. The negative angle tends to shear off the material instead of sliding over the threads apart when sufficiently high axial forces are applied, resulting in structural failure or loss of the preferred ability to unscrew and reuse the threaded joint. 


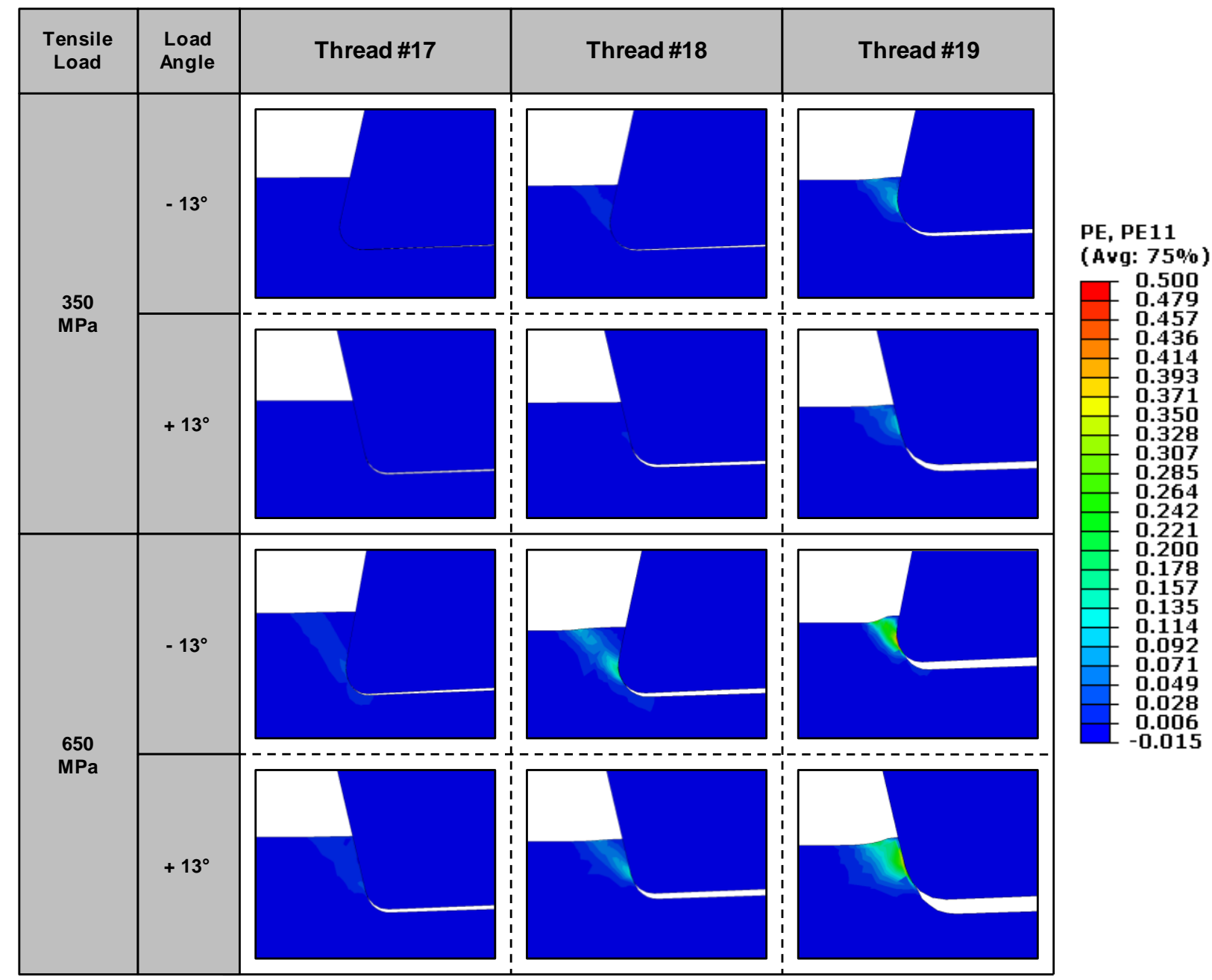

Figure 4: Schematic overview of the magnitude and location of the plastic zones at the last three engaged threads represented by the axial plastic strains for connections with a load angle of -13 and +13 degrees in combination with a tensile load of 350 and $650 \mathrm{MPa}$.

\section{Location on Crest of Thread 18 [-]}

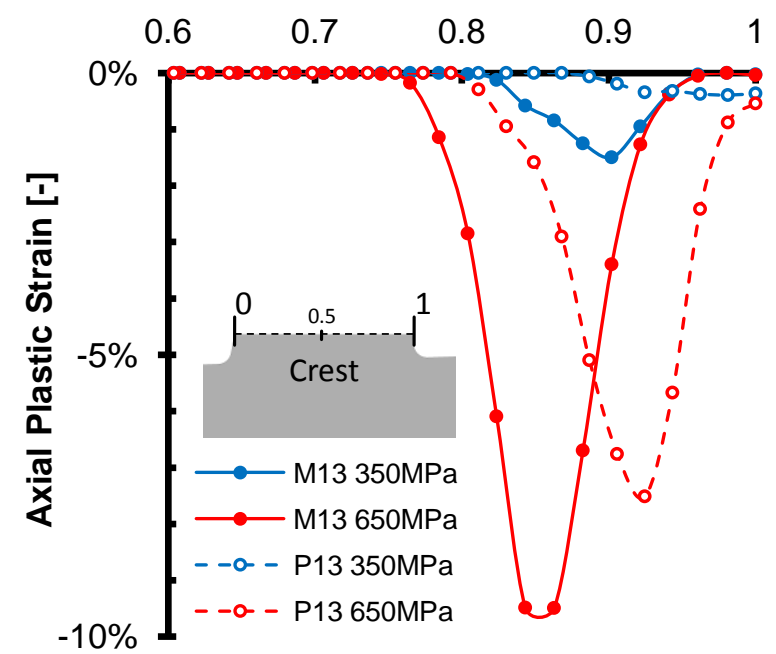

Figure 5: Axial plastic strain across the crest of thread 18.

\section{Location on Crest of Thread 19 [-]}
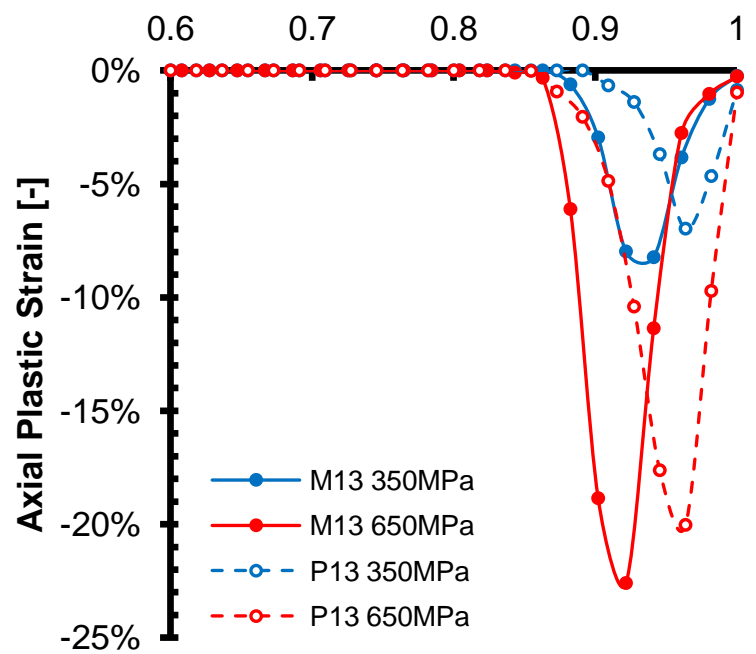

Figure 6: Axial plastic strain across the crest of thread 18. 


\subsubsection{Jump-out}

By using a positive load flank angle, the amount of plasticity can be reduced significantly. However, this will cause the threads to slide over each other, creating an inward displacement of the pin and an outward displacement of the box. When the relative displacement of pin and box increases, the sealability of the connection reduces. In extremis, when the displacement exceeds the height of the thread, this can lead to a separation of pin and box resulting in connection failure. This phenomenon is known as jump-out.

The radial displacement of the last engaged thread for connections with a positive (Figure 7) and a negative (Figure 8) load flank angle of 13 degrees are given below. Using the negative load flank angle in combination with a $650 \mathrm{MPa}$ axial load results in an average, relative displacement of approximately $55 \mu \mathrm{m}$. When the, from plasticity point of view, beneficial positive angle is used, the relative displacement increases up to $68 \mu \mathrm{m}$. This $20 \%$ increase in displacement results in a marginally higher probability to jump-out.

Related to this displacement, a slight rotation of the root of the pin can be observed and might result from the orientation of the engaged load flanks. While the positive flanks slide over each other, the negative flank of the box tends to stick behind the flank of the pin. This causes the entire thread to rotate and higher stress concentrations are present at the radius connecting the root and the load flank of the box.

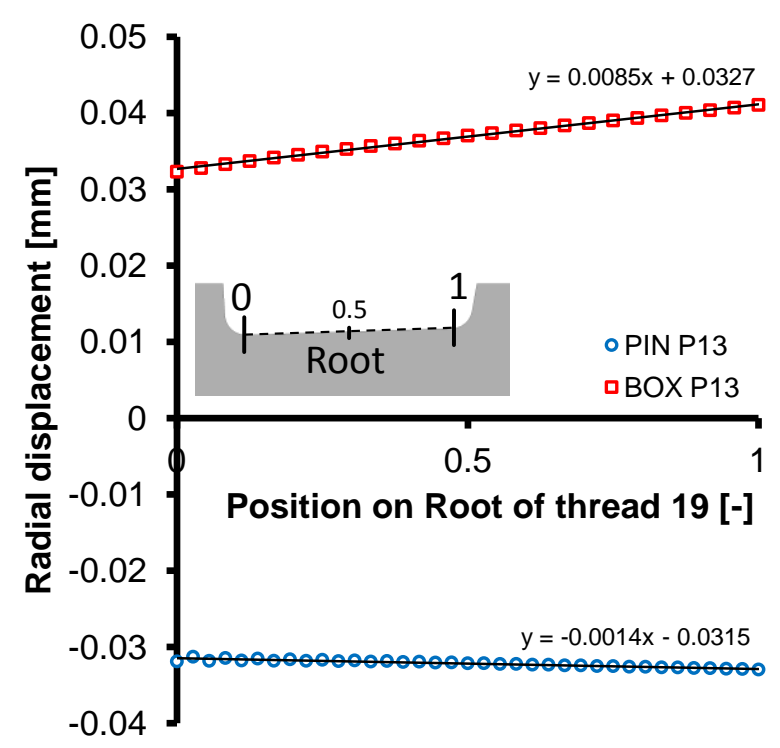

Figure 7: Relative displacement between pin and box at the LET for a connection with a positive load flank angle of 13 degrees and a 650MPa tensile load applied.

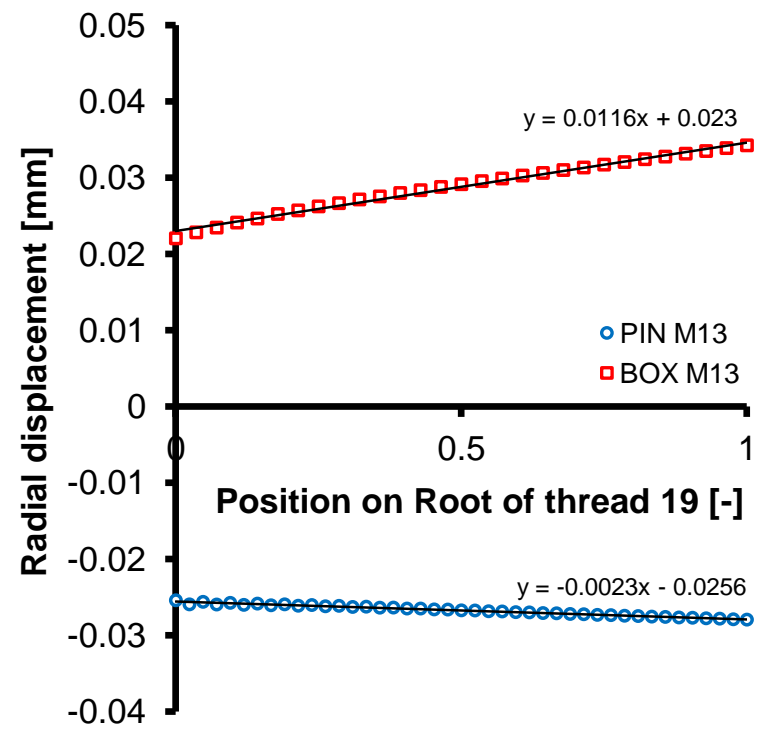

Figure 8: Relative displacement between pin and box at the LET for a connection with a negative load flank angle of 13 degrees and a $650 \mathrm{MPa}$ tensile load applied.

\subsubsection{Damage mechanisms}

When relative displacement of the threads on pin and box is present (as described above) combined with high contact stresses, severe damage can occur within the contact area. The slip at the load flanks for threads 18 and 19 is illustrated in Figure 9 and Figure 10. From both figures it is noticeable that for a negative load flank angle, no relative slip occurs at the top of the load flank and a peak appears near the bottom. In contrast, a positive load flank angle results in slip in the upper part of the load flank only.

From the contact pressure evolution, shown in Figure 11 and Figure 12, it appears that the magnitude of contact pressure at thread 18 and 19 is around $800 \mathrm{MPa}$ and $1000 \mathrm{MPa}$ respectively for both load flank angle configurations, regardless of the applied axial load. Despite these similarities, the length of contact is found to be slightly less when a positive load flank angle is used.

When comparing the contact pressures in the first part of load flank 18 with the slip, a contact is present without relative motion when a negative load flank angle is used. For the second half however, both contact pressures and slip can be observed. This finding might indicate that galling can take place in the contact. 


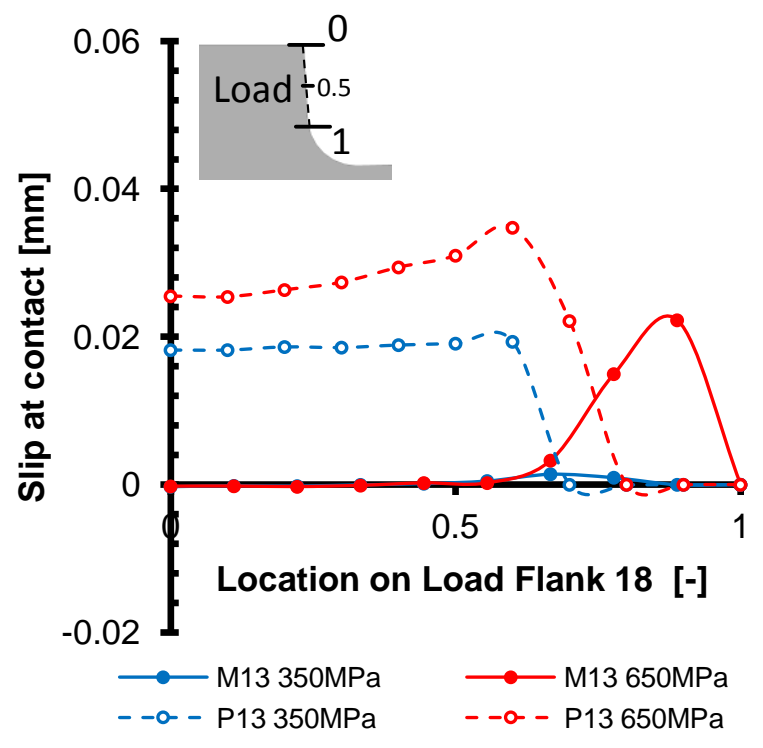

Figure 9: Representation of the slip occurring at the load flank of thread 18 on the pin.

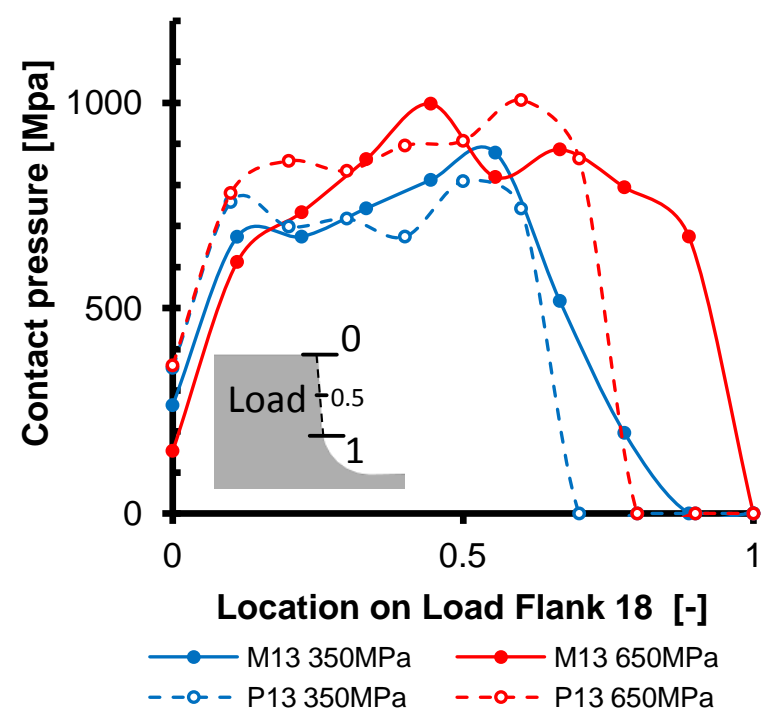

Figure 11: Magnitude of the contact pressure over the load flank of thread 18 of the pin

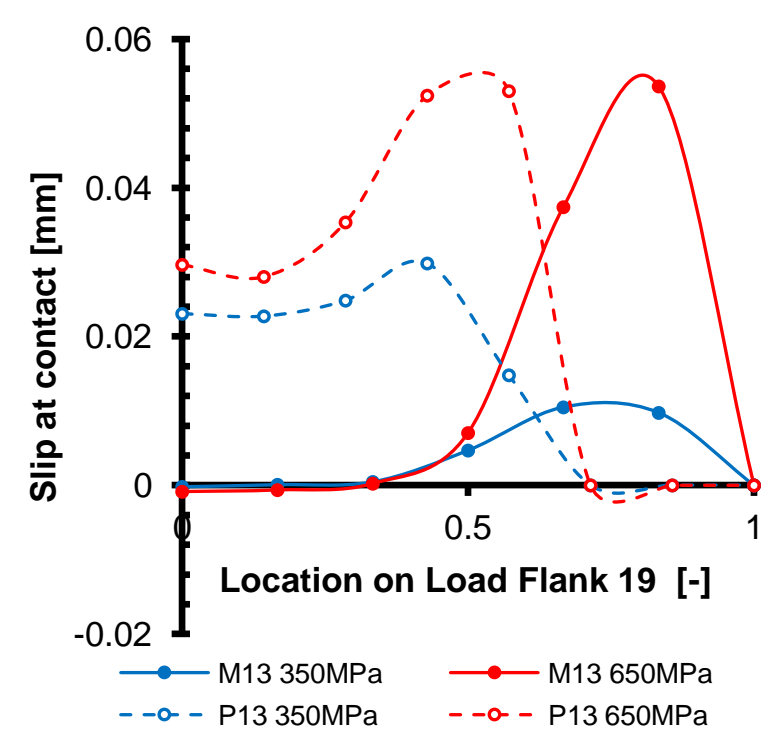

Figure 10: Representation of the slip occurring at the load flank of the LET of the pin.

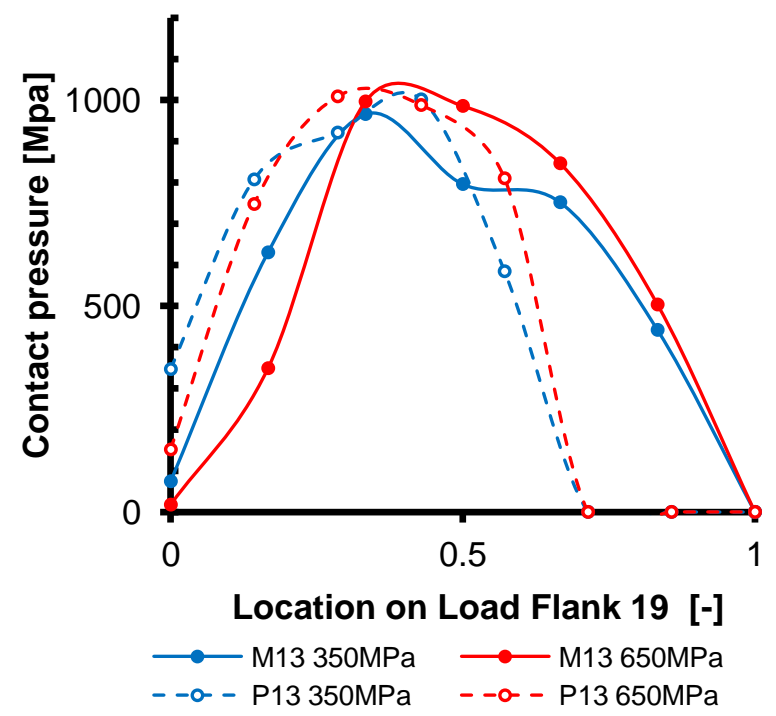

Figure 12: Magnitude of the contact pressure over the load flank of the last engaged thread of the pin

\section{CONCLUSIONS}

In an effort to increase the mechanical integrity of a threaded connection, the geometric parameters of the threaded profile can be altered. By changing the load flank angle, the tensile capacity can be improved. However, it should be noted that duality occurs and increasing the resistance against one failure mechanism can reduce the resistance against another mechanism which is initially not considered. A numerical study showed that, when reducing the risk of jump-out by using a negative load angle, the plasticity at the last engaged threads increases. These plastic deformations can cause loss of reusability when exceeding certain limits. Furthermore, the use of a negative load angle can increase the risk of galling.

For this reason, the thread profiles used in drill strings avoid the use of negative load flank angles, despite their higher tensile ratings. However, because of the absence of large cyclic loads and absence of the preference to reuse a connection, negative load flanks are often used when installing casings in oil wells. 


\section{REFERENCES}

[1] Walters, D., Thethi, R., A Step Change Application of Threaded and Coupled Connections, 2H Offshore Inc., USA, 2002

[2] Bradley, A.B., Premium Connection Design, Testing, and Installation for HPHT Sour Wells, Society of Petroleum Engineers Inc, SPE High Pressure-High Temperature Sour Well Design Applied Technology Workshop, 17-19 May 2005, The Woodlands, Texas, U.S.A., SPE 97585

[3] Kawashima, H., Effect of Incomplete Threads on the Jump-Out Tensile Failure of Premium Connections for Oil and Gas Wells, JSME International Journal, 33(1), 107-112, 1990

[4] Hilbert, L.B., Kalil, I.A., Evaluation of Premium Threaded Connections Using Finite-Element Analysis and Full-Scale Testing, IADC/SPE Drilling Conference, New Orleans, Louisiana, February 18-21, 1992

[5] Takano, J., Yamaguchi, M., Kunishige, H., Development of Premium Connection "KSBEAR" for Withstanding High Compression, High External Pressure, and Severe Bending, Kawasaki Steel Technical Report, 47, 2002

[6] Van Wittenberghe, J., Galle, T., De Baets, P., De Waele, W., Numerical Modelling and Experimental Validation of a Threaded Pipe Connection under Axial Tension, Mechanical Engineering Letters, 5, 8994, 2011

[7] Assanelli, A.P., Dvorkin, E.N., Finite element Models of OCTG Threaded Connections, Computers \& Structures, 47(4/5), 725-734, 1993

[8] Morita, Y., Kawashima, H., Ishihara, K., Finite Element Simulation of Jump-Out Behavior of Threaded Pipe Joints Used in Oil-Producing Wells, Journal of Energy resources Technology, 110(3), 27-33, 1988 